\title{
An Evaluation of the Issue of Teenage Pregnancies in Alice South Africa
}

\author{
Nontando Jennifer Mesatywa ${ }^{1}$ \\ Tarisai Chikungwa² \\ Gift Kabasa ${ }^{3}$ \\ 1 University of Fort Hare, Dept. of Social Work, \\ Private Bag, X1314, Alice, 5700, South Africa \\ Cell: +27721149832; Email: nmesatywa@ufh.ac.za \\ 2 University of Fort Hare, Govan Mbeki Research and Development Centre, \\ Private Bag, X1314, Alice, 5700, South Africa \\ Cell: +27737753063; Fax:+2786 620 7721; Email: tariechik@gmail.com; tchikungwa@ufh.ac.za \\ 3University of Fort Hare, Dept. of Business Management, \\ Private Bag, X1314, Alice, 5700, South Africa \\ Cell: +27836854401; Email: kabasagift@yahool.com
}

\section{Doi:10.5901/mjss.2013.v4n14p89}

\begin{abstract}
The study focused on teenage support programs in Alice, Nkonkobe Municipality with an emphasis on those support programs that dealt with pregnant teenagers. Did pregnant teenagers receive enough support from government, non-governmental organisations and the community at large? The main aim of the research was to ensure that effective support programs were in place to improve the wellbeing of teenagers and vulnerable children. The study wanted to show government and other support networks that they must be oriented towards meeting the needs of teenagers through a wide range of support programs. Irrespective of the hierarchical procedures in which organizations operate, emphasis should be put on understanding and meeting the needs of pregnant teenagers, ensuring their autonomy, self- reliance, sense of belonging, generosity, independence and mastery during the process of their development. It is important to include pregnant teenagers in decision making process to enable the formulation of effective policies and support programs which carter for their needs.
\end{abstract}

Keywords: Teenagers, pregnancy, alcohol, abuse, grants

\section{Introduction}

Teenage Pregnancy is a socioeconomic challenge and public health problem for communities in South Africa. Teenage pregnancy remains a challenge to the health professionals as it has the potential to lead to life-threatening obstetrical and medical complications. Potential obstetrical complications include pregnancy-induced hypertension and diabetes that leads to placental abruption and prematurity (Cronje \&Grobler, 2006:666). Teenage pregnancy is also a risk for transmitted infections (STIs), including HIV and is a reflection of inconsistent use of contraception. In addition, the risk of dropping out of school is considerable, which results in a lack of qualification and future unemployment. Some teenagers might struggle to keep their pregnancies till full term or deliver their babies normally due to their small pelvic spaces. Pregnant teenagers might deliver their babies prematurely, have prolonged labour or deliver only with assistance or caesarean sections (De Kock\& Van der Walt, 2004:23.3). Besides the medical and obstetrical complications for the families Teenage pregnancy has been associated with frequent sex without reliable contraception, sexual coercion, and poor sexual communication between partners. (Bezuidenhout, 2006:43) Liberal attitudes towards sex, alcohol consumption, fear of hormonal contraceptives and poor school based sexual education have also been associated with the proliferation of teenage pregnancy.

South Africa's teenage pregnancy rates remain high in the rural areas as compared to the cities and, in the rural town of Taung, the rate of $13 \%$ is twice the national average of $6.5 \%$. The teenage pregnancy rates in South Africa are the $1^{\text {st }}$ highest among 46 industrialized countries. In a survey carried out in 2003 , it was determined that $12 \%$ of South African teenagers (15-19 years) were or had been pregnant in their lives. The proportion of teenagers who had been pregnant rose rapidly with each year of age- from 15 years (2\%) to 19 years (27\%). Research in South Africa indicated 
that approximately $19 \%$ of teenagers who had sexual intercourse became pregnant. The birth rate of unmarried South African women aged (15-19 years) quadruped from 1960 to 1992, reaching a peak in 1991. According to the National Campaign to Prevent Teen Pregnancy (2007), the teenage birth rate decreased by 33.5\% between 1991 and 2004 . While the number of teenage pregnancies has declined in recent years, there is still a great need for support of parenting skills.

Review of successful teenage parenting and pregnancy programs have indicated that three components appear to have a long-term impact on the life outcomes of the mother and the baby: these are prenatal care, continuing educational support with child care and postpartum family planning (Williams \& Sadler, 2001).

\section{Background of the study}

\subsection{Literature Review}

Teenage pregnancy is a socioeconomic challenge and an important public health problem for communities in South Africa. Teenagers who fall pregnant are most likely to live a miserable life and multiply economic burden on their families (Kazembe, A, 2009). It is a risk factor for sexually transmitted diseases (STDs), including Human Immune-Deficiency virus (HIV), and is a reflection of inconsistent use of contraception. Moreover, the risk of dropping out of school is considerable, which results in a lack of qualifications and future unemployment.

\subsection{Defination of Teenage Pregnancy}

Teenage pregnancy is defined as an under aged girl between the age of $13-19$ falling pregnant. It has been associated with frequent sex without reliable contraception, sexual coercion, poor sexual communication between partners, and the perception that most of your friends have been pregnant or that one has to prove one's fertility, poverty and promiscuity. Health workers are accused of turning away teenagers from sexual educating programmes and giving them inadequate explanation saying they are young. This contributes to a low uptake of contraception by teenagers, despite it being free (Christine and William, 2001).

\subsection{Causes of Teenage Pregnancy}

People usually are afraid to talk about sex issues and relationships to teenagers which cause teenage pregnancy.

\subsubsection{Lack of Sex Education}

This is a vital issue that is lacking in most teenagers. Parents do not educate their children on matters of pregnancy and other aspects such as HIVIAIDS. They do not equip them with the realities of adult life and mostly they over protect them. This will result in lack of sex education to teenagers as a result ending up having teenage pregnancy, it's the parents to be blamed (Kidman, Petrow and Heyman, 2007).

\subsubsection{Psychological factors}

The immature and irresponsible behavior arising from complex teenage psychology is another important cause of teenage pregnancies. In addition weak family relationships, peer pressure and their own transition from childhood may result in depression which forces teenagers to seek love and support from people especially members of the opposite sex.

\subsubsection{Adolescent sexual behavior}

At the adolescent stage of growth, teenagers tend to be curious about sexual topics. This curiosity is exacerbated by the careless approach of the mass media. In turn teenagers indulge in sexual behavior which combined with a lack of adequate sex education results in teenage pregnancy. 


\subsubsection{Lack of discipline and control}

Factors like alcohol and substance abuse accompanied by unrestricted interaction with the opposite sex can ignite the sparks of lust and passion in youngsters very easily, ultimately leading to teenage pregnancy.

Nonetheless, at times, parents put too many restrictions on their children, especially girls to protect them from dangers. Bells, (2011) notes that this overprotection gives rise to frustration and a feeling of not being loved and cared for. Thus, balancing the two is the key to avoiding this problem.

\subsubsection{Socio-economic factors}

Childhood environment, lower educational and income levels have also been associated with high rates of teenage pregnancy for they often lead to negligence towards birth control methods.

\subsubsection{Sexual abuse}

Sexual relationships between teenage girls and older men are more likely to end up in teenage pregnancy as compared to sexual relationships between teenage boys and girls.

\subsubsection{Outcomes}

Teenage pregnancies create a host of problems such as incomplete education, unemployment, poverty, social embrrassment and emotional traumus. Phiri and Webb(2002) intimate that bodies of teenage girls are not as developed as those of adult women in terms of childbearing, therefore, they are likely to face certain complications as well.

\subsubsection{Poor socioeconomic conditions}

Socioeconomic conditions such as unemployment, poverty, reliance on government grants and limited teenagers opportunities that give pressure on teenagers to become pregnant mostly in rural areas. In rural areas marriages stand to take place early because of traditional and family beliefs, like the need to reduce expenditure, sign of health and good gender relations. Teenage pregnancy call for attention to be accorded to adolescent groups in rural areas and implementation of community based activities that provide information, education, and proper communication to vulnerable high risk groups and Family Life Education for male also. Were Family Life Education (F.L.E.) is a useful programme for young adults to improve attitudes toward health behavior (De Bellis 2001).

\subsubsection{Effects of alcohol on risk of pregnancy}

According to Laura (2001) alcohol and drugs are seen as a way of relaxing and releasing stress, hence many teenagers would like to experiment with that and as a result many teenagers fall pregnant while intoxicated. Major effect of alcohol is that teenagers become more easily influenced and alcohol numbs the part of the brain that controls a person's behavior. A young virgin may become loud and promiscuous (Welman, Kruger and Mitchell, 2005). The person feels more comfortable and relaxed and their controlled behavior changes and became vulnerable to anything. This often lead to unwanted or unplanned and unprotected sex, which can lead to pregnancy because of alcohol impairs judgement. A survey conducted in South Africa to analyse activities to reduce teenage pregnancy and alcohol abuse. The results shows that there was a 34\% decrease in the use of alcohol, tobacco and marijuana among boys and a decline in unprotected sex, sexual frequency, violence and truancy.

Welman, Kruger and Mitchel (2005) observe, teenage females who are or were pregnant often mention that they did not have all the information that they needed to make positive decisions. This is because of schools have limited access today to non-teacher assistants. In the past non-teacher assistants were helpful because they were from the community and knew the students and their parents. Today there are fewer counsellors in schools, and psychologists are often shared between schools. Laura (2001) argues that with increased awareness and more available information in the schools at an earlier age, students will be helped in dealing with the pressures that seem to follow them today. Health education classes need to be increased rather than decreased. 


\subsubsection{Relation to Public Health}

Public health covers categories such as epidemiology, biostatistics and health services. Society, behavior and occupations can affect what happens to groups of people. Due to experimentation, use and abuse of drinking alcohol among teenagers has become a public health issue. It impairs the thinking process and can lead to unprotected sex which can lead to pregnancy in teenagers. (Kidman, Petrow and Heyman, 2007).

\subsubsection{Peer pressure and other influential factors}

Adolescents influence their peers by modelling behaviours and setting social norms. Peer pressure is often thought to be a negative force on adolescents, but this study demonstrates that it is more often a positive one. In determining the independent effect of peers on adolescent sexual activity and risk of pregnancy, authors controlled other factors such as family background and structure, parental influences, socio-demographics, and individual characteristics such as cognitive ability, academics, religion, extra-curricular activities and dating.

Peer influence operates at many levels, and the network of close friends and the larger peer group have more significant effects on the female adolescent than do best friends. Peer influence is most often positive. One possible explanation for this finding is that adolescent girls often possess the necessary skills to filter the negative influences of their high-risk friends and benefit from the protective influences of low-risk friends.

\subsubsection{Lack of information on reproductive health and use of contraceptives}

In a research conducted by Chan, Lee, and Chan (2002), it was established that poor basic understanding of reproductive health can contribute to the fact that teenagers do not take enough precautions to avoid pregnancy. The understanding of reproductive health was explored by testing their understanding of 'safe' days in the menstrual cycle and awareness of ovulation. Only three girls out of the 12 pregnant teenagers were aware of the concept of relative safe period for unprotected sex in the menstrual cycle.

Regarding ovulation, eight girls knew that women produce an egg, but had little understanding of the role of ovulation. Some teenagers knew almost nothing about contraceptives.

\subsection{Empirical Literature}

Literature shows that teenagers who are sexually active, are usually subjected to negative attitudes. The manner in which an individual expresses an attitude is said to vary, with individual differences occurring in both the direction of the attitude or the strength and intensity with which a particular attitude is held (Brehm, Kassin and Fein, 2002). A study by Tervo (2004) considered nursing students had the least negative attitudes towards teenagers who become pregnant. Procter and Hafner (2000) also did a study using inter actions with teenagers who become pregnant and the results shows that, the attitudes towards students among pregnant teenagers varies from student to student and also has an impact on their attitudes towards teenagers who are pregnant.

Research conducted by Braddock and Parish (2001), indicates that teachers and students held significantly more positive attitudes towards teenagers at school, than students studying medical technology. Chan, Lee, Yuen, and Chan (2002) compared the attitudes of life orientation students and business students in Hong Kong, and found the life orientation students held more positive attitudes than the business students concerning teenage pregnancy. In another study Chan (2002) found that freshmen (first year) life orientation students differed significantly in their overall attitude towards pregnant teenagers.

\subsection{Theoretical Framework}

Traditionally, in many cultures around the world, teenagers who fall pregnant were thought of as under the intention of getting social grants and using the money for their personal needs instead of meeting the needs of the baby, since they would often leave the baby under the care and the liability of the parents (Tait \& Purdie, 2000). 


\subsubsection{Behaviour Modification Theory}

Behavior Modification theory deals with prevention of pregnancy at a younger age, continuation of secondary education, and job training for both adolescent fathers and mothers. Also it highlights many factors over and above personal attitudes and beliefs, which influence young people's sexual behavior. Social norms and peer pressure, perceived behavioral control (self-efficacy) and risk images all play an important role in shaping both behavioral intention and, in young and/or inexperienced young people, behavioral willingness. The impact of these factors is mediated by 'preparatory sexual behaviors,' namely communication or talking with one's partner, accessing free contraception and carrying condoms. It is recommended that the marketing strategy focuses on influencing these preparatory behaviors rather than sex itself, and where possible, does so by influencing multiple factors.

\subsubsection{Social learning theory}

South Africa has evolved into a complex, urban, technologically oriented society where adolescents are bombarded with sexually provocative advertising and peer group pressure while receiving inadequate education in reproductive biology (Bachor, D, 2002). The theme is the need for at-risk populations to learn how to reduce risky sexual behaviors. The theory found that self-efficacy was significantly related to social support and discussion of risks, although not directly to condom use. Kelly and St. Lawrence (2000) reported that their population of focus (gay males not in settled relationships) recognized that they were at some risk for HIV and were generally interested in reducing HIV risk, but they did not behave in ways that provided the least risk. A university sample reported concern and seeking information about AIDS without much actual preventive behavior change (Fisher \& Miscovich, 1990).

\subsubsection{Feminist theory}

According to As De Vos (2002) statistics on teenage pregnancy shows that $33 \%$ of sexually active adolescents between the ages of 15 to 17 are in relationships that move too fast sexually and at least $29 \%$ report feeling pressured to have sex. Twenty five percent of sexually active adolescents use drugs or alcohol during sexual encounters, $51 \%$ claim that they tend to do more sexually under the influence of these substances than they normally would do and, one in five sexually active teenagers uses no method of contraception. According to Coley R.L (1998) statistics on teenage pregnancy illustrate that rates of teenage pregnancy are going down. However, the decrease in the adolescent birth rate has contributed roughly to $26 \%$ of the decrease in the number of children living in poverty, and to $68 \%$ of the decrease in the number of young children living in single family homes. In developing countries the rate of teenage pregnancy is high and it's an expression of a failure to help young girls dealing with sexuality for example not providing adequate knowledge of contraception and urban girls have become addicted to drugs, alcohol, and expensive lifestyles; to ensure that they have the money for their desires. This failure leads to not only pregnancies and abortions, but also to STDs and HIV and AIDS.

\subsubsection{Cultural theory}

According to Anne L.Dean intimates both cultural and personal internal representations are the central integrating factors in the pregnancy systems of the adolescents. She offers that the unconscious communication from mothers to daughters initiates a multi-stage process for which there is a spectrum of adaptive and non-adaptive outcomes. Also highlights that pregnancies are not the function of the sociocultural context per se, nor the mothers' life experiences, but rather the outcome of the manner in which mothers and daughters have come to emotionally and cognitively appraise the desirability of adolescent pregnancy within that context.

\section{Methodology}

\subsection{Research design}

The study adopt a case study design using the qualitative approach. This approach allowed for the in depth extraction of information and respondents to have a connection with researcher to allow face-value credibility. 


\subsection{Population}

Area of research is Nzululwazi High School in Ntselamanzi located in Alice town Eastern Cape. The population consists of Social Service providers and youth between the ages of $15 \& 19$ and research involved females.

\subsection{Sample}

A sample size of 10 teenagers was used in this study and one focus group composed of 5 members who are social service providers from the Department of Social Development, Hospital, Non -Governmental Organizations and Community leaders.

\subsection{Sampling procedure}

In this study, the researcher used a non-probability sampling. The researcher approached community leaders who keep records of affected teenage pregnancy and was given a list of 20 names. The researcher randomly select 10 names from that list of females and their address who were aged between 15 and 19.

\subsection{Data Collection method}

Data was collected through the use of in-depth interviews were semi-structured interviews was implemented, in order the interviewer to establish strong and more relevant answers. Different questions were asked to different people for example questions asked to service providers were mainly focused on the services they offer to the teenagers.

\subsection{Reliability}

In this study reliability was influenced by the relationships and rapport which was established between the researcher and the participants. Also it has been established by the researcher through providing clear explanations to the participants.

\subsection{Ethical considerations}

The study observed informed consent where, assurances of confidentiality and anonymity was given to all participants. Also they were briefed on the purpose and benefit of the study to the society.

\subsection{Data analysis}

Information gathered in Xhosa from participants was translated into English before it was analysed and interpreted. Data analysis was done using Interpretational Analysis.

\section{Discussion of Findings}

\subsection{Profile of Individual Participation}

Ten teenagers were included in the study and all of them were females aged 17 and 20 and also most of them live within their extended families.

\subsection{Profile of Service Providers}

The focus group comprise a social worker from Social Development; OVC officer of africare, VCT Counsellor of Msobomvu support group and a ward counsellor of Ntselamanzi community. These are in a strategic position to give relevant information on the support programs available and they deal directly with teenagers. 


\subsection{Themes}

\subsubsection{Theme 1: Community response to the Situation of Teenage Pregnancy in Alice}

\subsubsection{Awereness}

Karim (2005) mentioned that awareness and educational programs from different schools about teenage are playing an important role in conveying information about teenage pregnancy to the communities and school children. From the 10 teenagers who participated in the research, $80 \%$ indicated that they know much about contraceptives from their Social life skills classes at school and some indicated that they did not have a full understanding of what pregnancy was about they had an idea from what they learnt. This has resulted in the teenagers accepting their situation and understanding the dangers of teenage pregnancy. Focus group participants also pointed that they conducted awareness campaigns and educational programs through community volunteers to help communities to have a better understanding about teenage pregnancy. This is one of the findings from teenage who participated:

I have self-awareness and understand about the pandemic and I act responsibly as an individual. I have learnt about the parenting skills at the clinic.My community now has knowledge about contraceptives and they support teenagers who are pregnant.

\subsubsection{NGOs and CBOs coalitions, neighbours, friends, relatives and church}

Out of 10 individuals who were interviewed $80 \%$ indicated that they are receiving help from the Department of Social Development in form of social grants. $20 \%$ indicated that they are not receiving any social grant. Sometimes they get help from friends, relatives, neighbours, NGOs and the church.

\subsubsection{Tolerance}

As far as the attitude of the community members is concerned, respondents had mixed feelings. $30 \%$ of children interviewed indicated that community members accept them as they are and try to assist them where they can. 10\% indicated that they receive food parcels and $60 \%$ indicated that the community helps them through counselling and providing guidance. The majority of focus group participants pointed out that communities tolerate towards teenage pregnancy even if they cannot do anything to support teenage mothers. They do not isolate or discriminate against them. Foster (2002) points out that the community sometimes fails to assist teenagers because they do not show any willingness to work towards their livelihood. However, Williamson (2002) argues that it is not because teenage mothers do not know how to use the funds that they receive from Social Development wisely but that they tend to have many things that need money.

\subsubsection{Segregation}

Eight of the ten children who were interviewed (80\%) said that the community does not show any segregation towards teenage pregnancy. Their responses show that they do not face any kind of discrimination from anyone be it at home or in the communities they live in.

However, two of ten children who were interviewed (20\%) mentioned that only a small section of the community does not discriminate teenage mothers. After probing into the nature of discrimination the pregnant teenagers face, the respondents mentioned that pregnant teenagers face academic discrimination. The respondent cited that they struggle to pay for their fees and stationary.

Phiri \& Webb, (2002) notes that ideas that are presented on different radio stations and television play a pivotal role in educating communities about the types of contraceptives teenagers can use thus reducing segregation and other maltreatments. 


\subsubsection{Theme 2: Support Programs Available to Pregnant}

\subsubsection{Programs}

Out of the 10 individuals interviewed, $8(80 \%)$ mentioned that they benefited from social grants. Of these 8 individual respondents, 3 mentioned that they received child care grants, 4 mentioned that they received food parcels and 1 mentioned that she received counselling and medication. 2(20\%) out of the 10, one identified that she was benefiting from the pension of her late father who was a teacher and the other mentioned she was living on her grandmother's old age grant. The focus group indicated that the programs they provided to pregnant teenagers included counselling to teenagers; helping them through the trauma they usually suffer after they give birth, training them regain self-esteem and live autonomously. They also give child care grants, foster care grants, food parcels, and foster-care especially within the extended family and on certain exceptional cases they provide adoption services to the teenage mothers.

\subsubsection{Significance}

The 8 who received the grant have indicated that the grant is helpful even though it is not enough to fully meet the basic needs of the child. The 2 individuals who indicated that they received counselling, medication and child care grant also pointed out that the program helped them a lot in their plight and now they feel at ease with themselves and also their situations. The focus group also agreed to the inadequacy of their programs for pregnant teenagers. Schumacher and Millan, (1994) intimates that many of these children turn to their extended families, many of whom are already living in poverty or to overwhelmed orphanages and shelters for survival.

\subsubsection{Frequency}

Out of 10 individuals interviewed, 8 individuals indicated that they received the social grant and medication on a monthly basis. 1 child who claimed to have been visited by a social worker for counselling indicated that the service is just provided spontaneously. There is no timetable or schedule or work plan for the program activities. The 2 children who indicated that they received food parcels also said that there is no schedule for the provision of the service. They indicated that they only received the food parcels twice early this year and the service just disappeared without notice.

The focus group participants were also in accord saying that there is a gap in the frequency with which services are provided. They indicated that some of the programs are affected by lack of transport, shortage of staff and work backlog which makes travelling into the communities difficult.

\subsubsection{Theme 3. The type of Care Given to Pregnant Teenagers}

\subsubsection{Care givers}

Out of 10 children interviewed $80 \%$ indicated that they received the social grant. $20 \%$ received nothing at all and nobody attended to them. Out of these individuals who received the social grant, 6 received child support grant, counselling and medication. The 6 reported that social workers or health workers came to assess their home environments. Only 20\% indicated that they have never worked with any social workers or received counselling or any other form of help.

\subsubsection{Contentment}

None of the 10 individuals, who were interviewed, showed contentment with the services they received from different stakeholders. The respondents did not show a feeling of calm or satisfaction with these services especially the department of social development. Respondents felt that the services are not doing enough to meet their needs and the service providers are not identifying teenagers in need within the Alice community. 2 individuals indicated that they did not receive any aid from social services around.

Focus groups pointed out that the service providers, to a large extent, provide needed resources but are greatly hindered by lack of cooperation from other respective stakeholders who let the programs down for fear that their responsibilities might be taken over. However, there are some programs which try to meet the children's needs in all aspects. They try to cover basic human needs by focusing on the physical, psychological, cognitive, social and emotional 
aspects of pregnant teenagers and teenage mothers.

\subsubsection{Improvements of the program}

Out of the 10 students interviewed 80\% recommended that Social Development must consider increasing their support grant for babies. $20 \%$ indicated that they need the social grants since they are not receiving anything at all. One of the respondents desires to go back and continue grade 10. She suggested that the Department of Social Development must assist pregnant teenagers or teenage mothers by paying for their children's school fees since they do not have any source of income except the child support grant, of which not all children are receiving it.

Focusing groups noted that, there is a need for service providers to work together in order to improve the quality of services provided to teenage mothers as well as pregnant teenagers. This will reduce reduplication of services, for instance when one Non- Governmental Organization is providing food parcels, it is important for the other to provide medication such as ARVs to those infected with HIVIAIDS than to do what the other organisation is doing within the same area. They also said that they need the Department of Social Development and the Department of Health to improve their effectiveness in service delivery since they are not meeting all the needs of the children.

\section{Conclusion and Recommedations}

\subsection{Conclusions: theme 1: Community Response to the Situation of Pregnant Teenagers}

\subsubsection{Knowledge about Teenage Pregnancy}

Some children get the knowledge from the life skills lessons at school. While others obtain it from television broadcasts, magazines, friends and peers. Awareness campaigns have also proved vital in imparting knowledge to the community. This indicates that information reaches children from different angles that give more than just one way of understanding.

Recommendations drawn from conclusions:

The service providers should partner to ensure consistency and avoid sending mixed messages that affect the future of teenage mothers. They should also provide a constant update about teenage pregnancy to the community.

\subsubsection{Social networks}

Some individuals indicated that they received help from relatives, friends and neighbours which indicates that most of the pregnant teenagers/teenage mothers are taken care of within the extended family. It also indicates that the community takes the lead in caring for the children within their local environment. The Department of Health and Social Development also provide social support to pregnant teenagers.

Recommendations drawn from conclusions:

Service providers should also coordinate their effort through networking so that they can provide sustainable services to the pregnant teenagers and avoid duplication of efforts. There should also be follow ups to make sure that services reach the intended target groups and also to see how these children are taken care of within these extended families.

\subsubsection{Attitude of community members towards pregnant teenagers.}

There are mixed feelings within the community towards the teenagers who fall pregnant. While others are tolerant and understand their situation, still others are intolerant and refuse to support them in anyway.

Recommendations drawn from conclusions:

There is need to educate the community in caring and supporting teenage mothers even if they have nothing to offer in material terms.

\subsubsection{Challenges faced by pregnant teenagers}

Some teenagers indicate that the social grants they receive are not sufficient to cover babies needs. On the other hand some teenagers manipulate these grants and do not use them for the baby at all. Other teenagers do not even 
have these grants and nor the food to feed their babies. In terms of education other teenagers complained that they did not have stationery or the uniforms to attend.

Recommendations drawn from the conclusions:

There is need for the non-governmental organizations and the Department of Social Development to constantly make assessments to include children in the programs which might help them especially for prevention and proactive measures. Furthermore there is also need for the revision of policies in giving the social grants so that they can be sustainable to the children.

\subsection{Conclusions: Theme2: Support Programs Available to Pregnant Teenagers}

\subsubsection{Programs}

Some children indicated that they received social grants from the Department of Social Development which help them meet some of the baby's needs. Some children also mentioned that they received food parcels, counselling and medication, and baby formula milk from the Department of Health and Social Development.

Recommendations drawn from the conclusions:

The department of Social Development should ensure sustainability in the social grants in order to better meet the needs of children. There is also a need to ensure that counselling, food parcels and psycho-social support meet all the needs of the pregnant teenagers/mothers. There is also need for collaboration of social services providers to avoid duplication of efforts and also to ensure sustainability of these programs. The programs enlisted in the policy document need to be implemented in practice with the awareness of all service providers to avoid recidivism.

\subsubsection{Significance of the programs:}

Conclusion drawn from the findings:

The programs received by the pregnant teenagers, even though they indicated that they are not adequate, they are useful to these teenagers. Some programs are of life worth importance for example intervention programs on trauma, counselling, and self-esteem building services.

Recommendations drawn from the conclusions:

There is need for the service providers to form networks amongst themselves to give a full package that gives comprehensive and sustainable projects to the needy pregnant teenagers. There is also need for consistence in providing food aid to pregnant teenagers since their condition requires them to eat properly balanced meals.

\subsubsection{Frequency of receiving the services}

The pregnant teenagers who receive social grants receive them on a monthly basis which gives them a predictable monthly income. There is no regular follow up by the service providers and the food provision schedules which makes the services unreliable and unpredictable to the recipients.

Recommendations drawn from the conclusions:

There is need for consistence in providing food parcels since many teenage mothers have indicated that they have inadequate food and the money they receive will be channelled to other social needs. This will make the services sustainable, comprehensive and integrated.

\subsection{Conclusions: Theme 3: The Type of Care Given to Pregnant Teenagers}

\subsubsection{Social workers}

Social workers prioritize giving care to the pregnant teenagers especially the relatives and the community based organizations. Many pregnant teenagers receive care within the extended families which is a trend most followed in South Africa to keep the children in their local environment. The support by the service providers is not dependable since it is just spontaneous and unscheduled

Recommendations drawn from the conclusions:

The Department of Social Development should support community based initiatives to strengthen the efforts of the 
communities in harnessing their resources. Service providers should help the babies or children raised in extended families with the legal procedures for applying for the child support grants. The service providers should also give a schedule for providing services so that they become helpful, dependable and balanced.

\section{References}

As de Vos (2002) Research at Grassroots. Van Schaik publishers. South Africa.

Bachor, D.(2000). Reformatting Reporting Methods for Case Studies. Canada: University of Victoria .social work services.

Barker GK, Rich S. Influences on adolescent sexuality in Nigeria and Kenya: finding from recent focus group discussion. Studies in Family Planning 1992: 23:199-210.

Brehm, S. S., Kassin, S. M., \& Fein, S. (2002). Social Psychology. Boston, MA: Houghton

Chan, C.C. H. Lee, T. M. C., Yuen, H. K., \& Chan, F. (2002). Attitudes toward teenage pregnancy between Chinese rehabilitation and business students: An implication for practice. .Rehabilitation Psychology, 47(3), 324-338.

Coley RL, Hase-Lansdale PL. (1988; 53(2):152-6) Adolescent pregnancy and parenthood, recent evidence and future directions. Van Shaik publisher.

Cronje H.S \&Grobbler, C.J.F. (2006) Obstetrics in Southern Africa. Pretoria: Van schaik.

De Bellis, M. D. (2001). Developmental traumatology: The psychobiological development of maltreated children and its implications for research, treatment and policy. Development and Psychopathology, American Journal of Orthopsychiatry, 55(4), 530-40.

Foster G. (2002)Beyond education and Food;Psucological wellbeing of orphans in Africa. Acta Paeditrica. 91.

Fostre G. Makufa,G (1999)Community mobilization:Family and Community Interventions for children affected by AIDS. Stress Programme .Zimbabwe,Mutare.

Kazembe, A. (2009) Factors that influence sexual behaviour in young women. African Journal of Midwifery and Women's Health.

Phiri Sand Webb D, (2002) The impact of Hiv and AIDS on orphans and programs and policy responces.UNICEF,Flore.

Tervo, R. C., Palmer, G., \& Redinius, P. (2004). Health professional student attitudes teenage pregnancy. Clinical Rehabilitation, 18, 908-915. 
